\title{
Comparison of four digestibility markers to estimate fecal output of dogs
}

\author{
Isabella Corsato Alvarenga*, Charles G. Aldrich*,1 and Zhining Ou§ \\ *Department of Grain Science and Industry, Kansas State University, Manhattan, KS 66506; and §Department \\ of Statistics, Kansas State University, Manhattan, KS 66506
}

\begin{abstract}
Twelve adult beagle dogs (10.6 \pm $1.4 \mathrm{~kg}$ ) were fed extruded dog diets in which the starch sources were whole sorghum, sorghum flour, sorghum mill-feed, or an equal combination of rice, corn, and wheat. The experiment was conducted as a replicated Latin square design digestibility study. Estimates of fecal organic matter $(\mathrm{OM})$, crude protein $(\mathrm{CP})$, crude fat $(\mathrm{CF})$, and gross energy (GE) outputs were determined by four methods: total fecal collection (TFC), chromic oxide $\left(\mathrm{Cr}_{2} \mathrm{O}_{3}\right)$, titanium dioxide $\left(\mathrm{TiO}_{2}\right)$, and acid insoluble ash (AIA). The correlation among the fecal output estimates by the four methods by partial correlation coefficients from the Error SSCP
\end{abstract}

Matrix (Pearson) were considered significant at $P<0.05$. The external markers, $\mathrm{Cr}_{2} \mathrm{O}_{3}$ and $\mathrm{TiO}_{2}$, had a higher $(P<0.05)$ OM fecal output Pearson correlation to TFC than the intrinsic marker AIA $\left(R=0.931\right.$ for $\mathrm{Cr}_{2} \mathrm{O}_{3}$ vs. $\mathrm{TiO}_{2} ; R=0.559$ for $\mathrm{TFC}$ vs. $\mathrm{Cr}_{2} \mathrm{O}_{3} ; R=0.592$ for TFC vs. $\mathrm{TiO}_{2} ; R=0.291$ for AIA vs. TFC). Interestingly, $\mathrm{TiO}_{2}$ highly correlated $(P<0.05)$ to $\mathrm{Cr}_{2} \mathrm{O}_{3}(R=0.93$ for $\mathrm{OM})$, and was also correlated highly to TFC and AIA. The study suggests that $\mathrm{TiO}_{2}$ may be a preferred marker to estimate fecal output in dogs vs. $\mathrm{Cr}_{2} \mathrm{O}_{3}$. The use of AIA represents a potential option for determining digestibility for diets in which external markers are impractical.

Key words: AIA, chromic oxide, dogs, fecal output, titanium dioxide, total fecal collection

(C) The Author (s) 2019. Published by Oxford University Press on behalf of the American Society of Animal Science. All rights reserved. For permissions, please e-mail: journals.permissions@oup.com. This is an Open Access article distributed under the terms of the Creative Commons Attribution Non-Commercial License (http://creativecommons.org/licenses/by-nc/4.0/), which permits non-commercial re-use, distribution, and reproduction in any medium, provided the original work is properly cited. For commercial re-use,please contact journals.permissions@oup.com

$$
\begin{array}{r}
\text { J. Anim. Sci. 2019.97:1036-1041 } \\
\text { doi: 10.1093/jas/skz020 }
\end{array}
$$

\section{INTRODUCTION}

When a new pet food is being developed, it is common to evaluate diet digestibility in the target species to validate nutrition and safety of the product. Broadly, this provides information about acceptability, fecal output, stool consistency, nutrient utilization, and overall healthfulness. The total fecal collection method (Lindahl, 1963) is the gold standard to estimate apparent total tract digestibility (ATTD) in many animal species. This

${ }^{1}$ Corresponding author: aldrich4@ksu.edu

Received November 20, 2018.

Accepted January 7, 2019. method consists of collecting all feces excreted in a given period of time. However, collecting all feces is not always possible and may be fraught with a high degree of inaccuracy (Jagger et al., 1992). Total fecal collection is time consuming, requires meticulous planning, significant effort, and fulltime confinement of the animals. Dogs were confined individually for 4-5 days to allow total fecal collection is only supported by few animal care committees due to animal welfare concerns. Furthermore, animals held under full containment may step in feces, perform coprophagy, and quantitative collection may be complicated by structures and daily sanitation. This all leads to errors in true measurement of fecal output. 
Furthermore, in wild species or those animals that are free-ranging, it is impractical (Atkinson et al., 1984), and application to in home testing is unreliable.

An alternative to total collection is the use of markers to estimate fecal output and ATTD. Chromic oxide is a common marker used in animal nutrition. It is the established standard for determination of metabolizable energy in pet foods according to AAFCO (2018). However, there are recognized issues with this chemical for health (Peddie et al., 1982; Sales and Janssens, 2003) and consistency in results (Moore, 1957; Jagger et al., 1992). Titanium dioxide $\left(\mathrm{TiO}_{2}\right)$ has been evaluated in a number of studies with pets (Lôbo-Junior et al., 2001; Childs-Sanford et al., 2006; Hagen-Plantinga et al., 2014) and other animal species (Peddie et al., 1982; Jagger et al., 1992; Titgemeyer et al., 2001; Smeets et al., 2015) with good results. It also has the advantage over $\mathrm{Cr}_{2} \mathrm{O}_{3}$ of being a food color additive incorporated in food up to $1 \%$ (Code of Federal Regulations, 2015), so there are fewer concerns regarding animal and worker safety. Each of these external markers must be added to the food for analysis. Conversely, acid insoluble ash (AIA) is an internal marker present in some foodstuffs, which in many cases does not need to be added externally to the food. Some researchers have evaluated AIA for use to determine fecal output in different animal species (McCarthy et al., 1974; Vogtmann et al., 1975; McCarthy et al., 1977; Atkinson et al., 1984). Markers like $\mathrm{TiO}_{2}$ or acid insoluble ash (AIA), an internal marker, might prove beneficial to companion animal nutrition research. Therefore, the objective of the present study was to determine the relationships of these three different marker methods and TFC to estimate fecal output in dogs. The hypothesis was that all markers would be similar to TFC and would provide more animal welfare options for future digestibility studies.

\section{MATERIALS AND METHODS}

\section{Diets and Animals}

Four nutritionally complete and balanced diets (Table 1) were produced via extrusion processing as described previously by Alvarenga et al. (2018). The basal portions of the experimental diets were similar and the treatments differed primarily in the type of starch source: control (CON) a 1:1:1 mix of rice, wheat, and corn, which was exchanged for whole ground sorghum (WSD), sorghum flour (FLD), or sorghum mill-feed (MFD; Table1). External markers chromic oxide $(0.25 \%)$ and titanium dioxide $(0.40 \%)$ were added to the dry mix of all diets

Table 1. Experimental diets used to feed dogs: Control (CON), whole sorghum (WSD), sorghum flour (FLD) and sorghum mill-feed (MFD).

\begin{tabular}{|c|c|c|c|c|}
\hline Ingredients, $\%$ & $\mathrm{CON}$ & WSD & FLD & MFD \\
\hline Brewers rice & 21.2 & - & - & - \\
\hline Corn & 21.2 & - & - & - \\
\hline Wheat & 21.2 & - & - & - \\
\hline Whole sorghum & - & 64.7 & - & - \\
\hline Sorghum flour & - & - & 63.11 & - \\
\hline Sorghum mill-feed & - & - & - & 67.6 \\
\hline Chicken by-product meal & 20.9 & 20.0 & 20.0 & 20.0 \\
\hline Chicken fat & 5.34 & 5.52 & 6.69 & 3.29 \\
\hline Beet Pulp & 4.00 & 4.00 & 4.00 & 4.00 \\
\hline Corn gluten meal & 2.35 & 2.35 & 2.35 & 2.35 \\
\hline Calcium carbonate & 0.75 & 0.35 & 0.26 & 0.67 \\
\hline Potassium chloride & 0.49 & 0.52 & 0.65 & 0.19 \\
\hline Salt & 0.46 & 0.45 & 0.47 & 0.43 \\
\hline Dicalcium phosphate & 0.87 & 0.95 & 1.27 & 0.24 \\
\hline Choline chloride & 0.20 & 0.20 & 0.20 & 0.20 \\
\hline Vitamin premix $^{1}$ & 0.15 & 0.15 & 0.15 & 0.15 \\
\hline Trace mineral premix ${ }^{2}$ & 0.10 & 0.10 & 0.10 & 0.10 \\
\hline Natural antioxidant & 0.07 & 0.07 & 0.07 & 0.08 \\
\hline Chromic oxide & 0.25 & 0.25 & 0.25 & 0.25 \\
\hline Titanium dioxide & 0.40 & 0.40 & 0.40 & 0.40 \\
\hline
\end{tabular}

${ }^{1}$ Vitamin premix $=$ calcium carbonate, vitamin E supplement, niacin supplement, calcium pantothenate, vitamin A supplement, thiamine mononitrate, pyridoxine hydrochloride, riboflavin supplement, vitamin D3 supplement, biotin, vitamin B12 supplement, and folic acid.

${ }^{2}$ Trace mineral premix $=$ calcium carbonate, zinc sulfate, ferrous sulfate, copper sulfate, manganous oxide, sodium selenite, and calcium iodate. 
prior to extrusion. This assures consistent uniform dosage and avoids potential losses due to fines and spillage during feeding. Diets were produced on a single screw extruder (model X25; Wenger Mfg., Sabetha, KS) and dried on a 2 pass dryer/1 pass cooler (model 4800 Wenger, Mfg., Sabetha, KS), then coated with chicken fat prior to packaging. Product was stored in ambient conditions in multi-walled poly lined bags for 4 weeks before commencement of the feeding study.

Twelve intact Beagle dogs, eight males and four females, 1-3 years old, with average body weight of $10.6 \pm 1.42 \mathrm{~kg}$ were fed the experimental diets during four periods of 9 days adaptation and 5 days total fecal collection each, in a replicated Latin square design (Kim and Stein, 2009) experiment. Total feces were collected from the Beagle dogs during each of the four collection periods twice daily (08:00 and 17:00), and animal care and handling are described by Corsato Alvarenga and Aldrich (2018). All animal testing was approved by the Kansas State University Institutional Animal Care and Use committee (IACUC; protocol number 3645) prior to the conduct of the study.

\section{Nutrient analyses}

At the conclusion of the feeding study, total feces of each dog during each period were dried in a convection oven (Cat 52755-20, Matheson Scientific, Morris Plains, $\mathrm{NJ}$ ) at $55^{\circ} \mathrm{C}$ until dry to the touch (24-48 h), and then ground to pass a $0.5 \mathrm{~mm}$ screen in a fixed blade hammermill (Retsch, Newtown, PA, USA). A small portion of dry feces $(1 \mathrm{~g})$ was incinerated at $600^{\circ} \mathrm{C}$ for $8 \mathrm{~h}$ in a muffle furnace (model F30400: Thermo Scientific Thermolyne Furnace, Asheville, NC) to determine ash and organic matter (OM) content (AOAC 942.05). Fecal gross energy (GE) was determined by bomb calorimetry (model 1341, Parr Instruments Company, Moline, IL). Fecal crude protein (CP; AOAC 990.03) and crude fat (CF; AOAC 945.16) were determined at a commercial laboratory (Midwest Laboratories, Omaha, NE).

\section{Digestibility markers measurements}

Chromium was measured in feces by atomic absorption using the protocol described by Williams et al. (1962). Titanium in feces was measured using a colorimetric method according to the protocol described by Myers et al. (2004). Acid insoluble ash in feces and food was determined according to the protocol described by Van Keulen and Young
(1977), with slight modification. Briefly, $4 \mathrm{~g}$ of dry feces or $10 \mathrm{~g}$ of food were weighed in porcelain crucibles on an analytical balance (Explorer: E1RW60, OHAUS, Parsippany, NJ) and ashed at $600^{\circ} \mathrm{C}$ for $8 \mathrm{~h}$ in a muffle furnace (model F30400: Thermo Scientific Thermolyne furnace, Asheville, NC). These were then boiled in $2 \mathrm{~N}$ hydrochloric acid $(\mathrm{HCl})$ for $5 \mathrm{~min}$ before being filtered under vacuum (DOA-V120-AE: Gast Manufacturing, Inc., Bonton Harbor, MI, USA) through ashless filter paper (541: Whatman, Maidstone, UK), and then ashed again at $650^{\circ} \mathrm{C}$ overnight (approximately $12 \mathrm{~h}$ ). The samples were weighed after the second ashing to estimate the AIA percentage.

\section{Fecal Output Calculations}

There were in total 48 fecal samples $(12$ dogs $\times$ 4 diets) used to calculate fecal output according to TFC or marker method. Total fecal collection fecal output (using organic matter as an example) was determined by the following equation:

OM fecal output $(\mathrm{TFC})=\% \mathrm{OM}$ in feces $\times$ total feces on

DM basis $(\mathrm{g})$

Fecal output determined by external markers $\mathrm{Cr}_{2} \mathrm{O}_{3}$ and $\mathrm{TiO}_{2}$, and internal marker AIA (using organic matter as an example) were calculated using the following equation:

$\mathrm{OM}$ fecal output (markers) $=\frac{\begin{array}{c}\% \mathrm{OM} \text { in feces } \times \text { marker } \\ \text { ingested in food }(\mathrm{g})\end{array}}{\% \text { marker in feces }}$

\section{Statistical Analysis}

Pearson correlation coefficients between methods used to estimate fecal output (TFC, AIA, $\mathrm{Cr}_{2} \mathrm{O}_{3}$, and $\mathrm{TiO}_{2}$ ) were determined with multivariate analysis of variance (MANOVA) on three response variables: diet, period, and dog, using the generalized linear model (GLM) procedure with the aid of a statistical software (SAS, version 9.4). Correlation coefficients were considered significant at $P<0.05$.

\section{RESULTS AND DISCUSSION}

The experimental diets comprised of $63.6 \%$ cereals from equal proportions of rice, corn, and wheat $(\mathrm{CON})$, or a similar amount of sorghum as whole (WSD), flour (FLD), or mill-feed (MFD; 
Table 2. Nutrient analysis of experimental diets control (CON), whole sorghum (WSD), sorghum flour (FLD) and sorghum mill-feed (MFD) fed to dogs.

\begin{tabular}{lcccc}
\hline \hline Nutrient & CON & WSD & FLD & MFD \\
\hline Dry matter, \% & 93.9 & 93.6 & 94.8 & 93.8 \\
Organic matter, \% & 92.7 & 93.5 & 93.4 & 93.1 \\
Crude protein, \% & 21.5 & 21.4 & 21.2 & 23.8 \\
Crude fat, \% & 12.10 & 10.7 & 10.25 & 9.48 \\
Gross Energy, kcal/g & 4,311 & 4,329 & 4,490 & 4,415 \\
TDF, \% & 4.73 & 7.57 & 4.33 & 16.39 \\
Ash, \% & 7.24 & 6.52 & 6.59 & 6.86 \\
\hline
\end{tabular}

Table 3. Partial Correlation Coefficients from the Error SSCP Matrix ${ }^{1}$ (Pearson) evaluating methods ${ }^{2}$ to determine organic matter, crude protein, crude fat and gross energy fecal outputs by dogs in which dietary treatment data were pooled.

\begin{tabular}{|c|c|c|c|c|c|c|c|c|}
\hline & \multicolumn{2}{|c|}{ Organic matter } & \multicolumn{2}{|c|}{ Crude protein } & \multicolumn{2}{|c|}{ Crude fat } & \multicolumn{2}{|c|}{ Gross energy } \\
\hline & $R^{2}$ & $P$-value & $R^{2}$ & $P$-value & $\mathrm{R}^{2}$ & $P$-value & $\mathrm{R}^{2}$ & $P$-value \\
\hline$\overline{\mathrm{TFC}}$ vs. $\mathrm{Cr}_{2} \mathrm{O}_{3}$ & 0.559 & $<0.0001$ & 0.569 & $<0.0001$ & 0.635 & $<0.0001$ & 0.563 & $<0.0001$ \\
\hline $\mathrm{TFC}$ vs. $\mathrm{Ti}_{2} \mathrm{O}$ & 0.592 & $<0.0001$ & 0.613 & $<0.0001$ & 0.685 & $<0.0001$ & 0.600 & $<0.0001$ \\
\hline TFC vs. AIA & 0.291 & 0.0446 & 0.326 & 0.0238 & 0.410 & 0.0038 & 0.328 & 0.0038 \\
\hline $\mathrm{Cr}_{2} \mathrm{O}_{3}$ vs. $\mathrm{Ti}_{2} \mathrm{O}$ & 0.931 & $<0.0001$ & 0.914 & $<0.0001$ & 0.919 & $<0.0001$ & 0.929 & $<0.0001$ \\
\hline $\mathrm{Cr}_{2} \mathrm{O}_{3}$ vs. AIA & 0.749 & $<0.0001$ & 0.731 & $<0.0001$ & 0.774 & $<0.0001$ & 0.776 & $<0.0001$ \\
\hline $\mathrm{Ti}_{2} \mathrm{O}$ vs. AIA & 0.842 & $<0.0001$ & 0.821 & $<0.0001$ & 0.861 & $<0.0001$ & 0.864 & $<0.0001$ \\
\hline
\end{tabular}

${ }^{1}$ Coefficient of correlation significant at $P<0.05$.

${ }^{2} \mathrm{TFC}=$ total fecal collection; $\mathrm{Cr}_{2} \mathrm{O}_{3}=$ chromic oxide; $\mathrm{TiO}_{2}=$ titanium dioxide; $\mathrm{AIA}=$ acid insoluble ash.

Table 1). Dietary treatments met the goal of being similar in crude protein (range 21.2-23.8\%), crude fat (range 9.48-12.10\%; Table 2), vitamins and minerals.

Estimation of animal dietary utilization in measures such as digestibility typically rely on calculating the difference between intake and output. Intake is typically controlled and easily measured. However, fecal output, while ostensibly a single measure, can be challenging for a myriad of reasons. Measurement of fecal output can be done by collection of all feces excreted during a determined period, which is the gold standard method, or by collecting fecal aliquots and measuring the proportion of a marker. It is generally considered that a substance can be used as a marker for digestibility if it is unabsorbed and undigested by the animal, if it mixes homogenously with the digesta through the gut, and if it is pharmacologically inactive within the digestive tract (Schneider and Flatt, 1975; Maynard et al., 1979).

To be most effective, markers like $\mathrm{Cr}_{2} \mathrm{O}_{3}$ and $\mathrm{TiO}_{2}$ need to be provided in a constant quantity. Addition to the diet fulfills this need. In the present study the TFC method had significant correlations with $\mathrm{Cr}_{2} \mathrm{O}_{3}$ and $\mathrm{TiO}_{2}$ (range $R^{2}=0.559$ to 0.685 for OM, CP, CF, and GE fecal outputs; Table 3). In growing pigs, ATTD of energy and DM were slightly lower when determined by $\mathrm{TiO}_{2}$ compared with TFC method, while estimations by $\mathrm{Cr}_{2} \mathrm{O}_{3}$ were similar to the extremes (Kavanagh et al., 2001). In a study with dogs, ATTD of DM, CP, $\mathrm{CF}$, and $\mathrm{GE}$ determined by $\mathrm{Cr}_{2} \mathrm{O}_{3}$ were also similar to TFC (Lôbo-Junior et al., 2001). Likewise, Hill et al. (2009) reported that apparent nutrient digestibility coefficients determined by TFC and $\mathrm{TiO}_{2}$ methods were not different in dogs. Although the correlation between TFC and external markers was intermediate in the present study, other studies suggest that both $\mathrm{Cr}_{2} \mathrm{O}_{3}$ and $\mathrm{TiO}_{2}$ are efficient fecal markers to estimate fecal output and ATTD of nutrients in dogs.

An interesting option to avoid the extra effort associated with adding a marker is to exploit something already present in the food (Atkinson et al., 1984). Acid insoluble ash (AIA) is an intrinsic mineral material found in food that is not digested or absorbed by the animal gut. This characteristic allows it to be used as a marker and it has been reported to be successful in determining apparent total tract digestibility in many animal species (McCarthy et al., 1974; Vogtmann et al., 1975; McCarthy et al., 1977; Atkinson et al., 1984). In horses, De Marco et al. (2012) found that DM, OM, GE, and CP digestibility determined by TFC and AIA methods were very similar numerically. Studies 
in dogs have also reported that AIA and TFC techniques estimate fecal output and nutrient digestibility with a high degree of accuracy (Lôbo-Junior et al., 2001; Zanatta et al., 2013). In contrast, the present study found that TFC and AIA had the poorest correlation for fecal output of all nutrients tested $\left(R^{2}=0.291,0.326,0.410\right.$, and 0.328 for OM, CP, GE, and CP, respectively; Table 1). Since TFC had low to intermediate correlations with internal and external markers, our concern was that TFC was not reflective of true fecal output and may have led to the inconsistent interpretation.

External markers $\mathrm{TiO}_{2}$ and $\mathrm{Cr}_{2} \mathrm{O}_{3}$ correlated highly for fecal outputs of all nutrients (OM, CP, $\mathrm{CF}$, and GE $R^{2}=0.931,0.914,0.919$, and 0.929, respectively; Table 3). Kavanagh (2001) also found that $\mathrm{TiO}_{2}$ and $\mathrm{Cr}_{2} \mathrm{O}_{3}$ estimated similar nutrient digestibility in growing pigs. The high correlation between external markers in the present study further confirms that TFC may have been inconsistent, which was possibly due to difficulties in collecting all feces, animals stepping on their stool, and coprophagy habits.

Despite having poor correlation with TFC, AIA in our study had an intermediate to high correlation with $\mathrm{Cr}_{2} \mathrm{O}_{3}\left(R^{2}=0.750,0.731,0.774\right.$, and 0.776 for $\mathrm{OM}, \mathrm{CP}, \mathrm{CF}$, and GE, respectively; Table 3) and even higher with $\mathrm{TiO}_{2}\left(R^{2}=0.842\right.$, $0.821,0.861$, and 0.864 for $\mathrm{OM}, \mathrm{CP}, \mathrm{CF}$, and GE, respectively, Table 3). Equivalently, Wang et al. (2017) found that in pigs all three markers $\mathrm{TiO}_{2}, \mathrm{Cr}_{2} \mathrm{O}_{3}$, and AIA gave similar results for energy and nitrogen digestibility, while TFC led to different digestibility estimates. Other studies with pigs reported similar ATTD determined by the AIA and $\mathrm{Cr}_{2} \mathrm{O}_{3}$ markers (Favero et al., 2014; Brestenský et al., 2017). This is encouraging because AIA may have beneficial applications for animals that cannot be fed prepared diets with added external markers. Thus, there is need to further explore the use of AIA as an intrinsic fecal marker for dogs. Caution must be used when determining AIA in feedstuffs with low ash levels (e.g., Alfalfa; Van Keulen and Young, 1977), as small discrepancies in analysis and sample preparation can unduly increase the variation and make interpretation difficult. Fortunately, most pet food formulas contain more than sufficient ash to be effective.

According to our study, $\mathrm{TiO}_{2}$ was the marker that best correlated with all other three methods. Jagger et al. (1992) also found that $\mathrm{TiO}_{2}$ was a better marker to estimate apparent total tract digestibility in pigs, when compared to $\mathrm{Cr}_{2} \mathrm{O}_{3}$. Titanium dioxide is a generally recognized as safe (GRAS) food coloring agent that is permitted in foods, including pet foods. It is commonly used to help lighten and (or) whiten foods for consumer visual appeal. Further, the method of sample preparation and analysis are simpler and require less sophisticated analytical equipment. Hence, $\mathrm{TiO}_{2}$ would be a more readily useable method for future research to determine diet utilization and caloric content of pet diets, and it should be a good alternative to the official marker for dogs and cats $\left(\mathrm{Cr}_{2} \mathrm{O}_{3}\right.$; AAFCO, 2018).

\section{CONCLUSION}

Titanium dioxide had the highest correlation to all markers in this study. It also has the benefit that it can be safely used as a food additive (Code of Federal Regulations, 2015) and the spectrophotometry method of analysis is relatively straightforward. AIA correlated intermediate to high with both $\mathrm{Cr}_{2} \mathrm{O}_{3}$ and $\mathrm{TiO}_{2}$, but had a low correlation with TFC. There is need to further explore the use of AIA as an intrinsic marker for estimating fecal output when addition of a marker into the diet is not possible. Future evidence of an acceptable alternative marker could provide with data to discontinue the use of $\mathrm{Cr}_{2} \mathrm{O}_{3}$ as a fecal marker and select options such as $\mathrm{TiO}_{2}$ or AIA.

The authors have no conflicts of interest.

\section{ACKNOWLEDGMENTS}

Financial support for this research was provided by the Sorghum Check-off Program.

\section{LITERATURE CITED}

AAFCO. 2018. Model regulations for pet food and specialty pet food under the model bill. In: S. Cook, section editor. Association of American Feed Control Officials, Inc., Champaign, IL. Pp. 107-232.

Alvarenga, I. C., Z. Ou, S. Thiele, S. Alavi, and C.G. Aldrich. 2018. Effects of milling sorghum into fractions on yield, nutrient composition, and their performance in extrusion of $\operatorname{dog}$ food. J. Cereal Sci. 82:121-128. doi: 10.1016/j. jcs.2018.05.013

Atkinson, J. L., J. W. Hilton, and S. J. Slinger. 1984. Evaluation of acid-insoluble ash as an indicator of feed digestibility in rainbow trout (Salmo gairdneri). Can. J. Fish. Aquat. Sci.. 41:1384-1386.

Brestenský, M., S. Nitrayová, J. Heger, and P. Patráš. 2017. Chromic oxide and acid-insoluble ash as markers in digestibility studies with growing pigs and sows. J. Anim. Physiol. Anim. Nutr. (Berl). 101:46-52. doi:10.1111/jpn.12503

Childs-Sanford, S. E., and C. R. Angel. 2006. Transit time and digestibility of two experimental diets in the maned wolf (Chrysocyon brachyurus) and domestic dog (Canis lupus). Zoo Biol. 25:369-381. 
Code of Federal Regulations. 2015. Title 21, Volume 1, Part 73: listing of color additives exempt from certification. Subpart A Foods Sec. 73.57. http://www.accessdata.fda. gov/scripts/cdrh/cfdocs/cfcfr/cfrsearch.cfm?fr $=73.575$ (last time accessed: June 30, 2016).

Corsato Alvarenga, I., and C. G. Aldrich. 2018. The effect of sorghum fractions on apparent total tract digestibility and antioxidant capacity by dogs. PLoS One 13:e0206090. doi:10.1371/journal.pone.0206090

De Marco, M., N. Miraglia, P. G. Peiretti, and D. Bergero. 2012. Apparent digestibility of wheat bran and extruded flax in horses determined from the total collection of feces and acid-insoluble ash as an internal marker. Animal. 6:227-231. doi:10.1017/S1751731111001297

Favero, A., D. Ragland, S. L. Vieira, A. Owusu-Asiedu, and O. Adeola. 2014. Digestibility marker and ileal amino acid digestibility in phytase-supplemented soybean or canola meals for growing pigs. J. Anim. Sci. 92:5583-5592. doi:10.2527/jas.2014-7919

Hagen-Plantinga, E. A., G. Bosch, and W. H. Hendriks. 2014. Felinine excretion in domestic cat breeds: a preliminary investigation. J. Anim. Physiol. Anim. Nutr.. 98:491-496

Hill, S. R., K. J. Rutherfurd-Markwick, G. Ravindran, C. E. Ugarte, and D. G. Thomas. 2009. The effects of the proportions of dietary macronutrients on the digestibility, post-prandial endocrine responses and large intestinal fermentation of carbohydrate in working dogs. N. Z. Vet. J. 57:313-318. doi:10.1080/00480169.2009.64718

Jagger, S., J. Wiseman, D. J. Cole, and J. Craigon. 1992. Evaluation of inert markers for the determination of ileal and faecal apparent digestibility values in the pig. $\mathrm{Br}$. J. Nutr. 68:729-739.

Kavanagh, S., P. B. Lynch, F. O'mara, and P. J. Caffrey. 2001. A comparison of total collection and marker technique for the measurement of apparent digestibility of diets for growing pigs. Anim. Feed Sci. Technol., 89:49-58.

Kim, B. G., and H. H. Stein. 2009. A spreadsheet program for making a balanced Latin Square design. Rev. Colom. Cienc. Pec., 22:591-596.

Lindahl, I. L. 1963. Techniques and procedures in animal production. Methods employed in nutrition research. Amer. Soc. Anim. Sci., New York, N.Y. p. 173-193.

Lôbo-Junior, M. F., A. S. C. Rezende, E. O. S. Saliba, and I. B. M. Sampaio. 2001. Determination of apparent digestibility coefficients either by markers or total fecal collection techniques in dogs. Arq. Bras. Med. Vet. Zootec. 53:691-694.

Maynard, L. A., J. K. Loosli, H. F. Hintz, and R. G. Warner. 1979. Animal nutrition. 7th ed. McGraw- Hill Book Company, London.

McCarthy, J. F., F. X. Aherne, and D. B. Okai. 1974. Use of $\mathrm{HCl}$ insoluble ash as an index material for determining apparent digestibility with pigs. Can. J. Anim. Sci. 54:107-109.

McCarthy, J. F, J. P. Bowland, and F. X. Aherne. 1977. Influence of method upon the determination of apparent digestibility in the pig. Can. J. Anim. Sci. 57:131-135.

Moore, J. H. 1957. Diurnal variations in the composition of the faeces of pigs on diets containing chromium oxide. Br. J. Nutr. 11:273-288.

Myers, W. D., P. A. Ludden, V. Nayigihugu, and B. W. Hess. 2004. Technical note: a procedure for the preparation and quantitative analysis of samples for titanium dioxide. J. Anim. Sci. 82:179-183.

Peddie, J., W. A. Dewar, A. B. Gilbert, and D. Waddington. 1982. The use of titanium dioxide for determining apparent digestibility in mature domestic fowls (Gallus domesticus). J Agric. Sci. 99:233-236.

Sales, J., and G. Janssens. 2003. The use of markers to determine energy metabolizability and nutrient digestibility in avian species. World's Poult. Sci., 59:314-327.

Schneider, B. H., and W. P. Flatt. 1975. The evaluation of feeds through digestibility experiments. University of Georgia Press, Athens, GA. p. 168.

Smeets, N., F. Nuyens, L. Van Campenhout, E. Delezie, J. Pannecoucque, and T. Niewold. 2015. Relationship between wheat characteristics and nutrient digestibility in broilers: comparison between total collection and marker (titanium dioxide) technique. Poult. Sci. 94:1584-1591. doi: $10.3382 / \mathrm{ps} / \mathrm{pev} 116$

Titgemeyer, E. C., C. K. Armendariz, D. J. Bindel, R. H. Greenwood, and C. A. Löest. 2001. Evaluation of titanium dioxide as a digestibility marker for cattle. J. Anim. Sci. 79:1059-1063.

Van Keulen, J. V., and B. A. Young. 1977. Evaluation of acid-insoluble ash as a natural marker in ruminant digestibility studies. J. Anim. Sci. 44:282-287.

Vogtmann, H., H. P. Pfirter, and A. L. Prabucki. 1975. A new method of determining metabolisability of energy and digestibility of fatty acids in broiler diets. Br. Poult. Sci. 16:531-534. doi:10.1080/00071667508416222

Wang, T., D. Ragland, and O. Adeola. 2017. Combination of digestibility marker and fiber affect energy and nitrogen digestibility in growing pigs. Anim. Feed Sci. Technol., 230:23-29.

Williams, C. H., D. J. David, and O. Iismaa. 1962. The determination of chromic oxide in feces samples by atomic absorption spectrophotometry. J. Agric. Sci. 59:381-385.

Zanatta, C. P., L. R. Gabeloni, A. P. Félix, C. B. M. D. Brito, S. G. D. Oliveira, and A. Maiorka. 2013. Methodology for determination of digestibility of diets containing vegetable or animal protein sources in dogs. Ciênc. Rural. 43:696-701. 